\title{
EPICURO E A NATUREZA DA ALMA
}

\author{
Maria da Glória Novak \\ Universidade de Săo Paulo
}

\section{Résumé}

La Lettre à Hérodote n'est qu'un résumé du point de vue d'Épicure et, encore, du moins a propos de l'âme, quelque peu obscur. Puisque du Maitre nous n'avons que trols lettres et quelques maximes, II nous a été nécessaire, voire indispensable, d’avoir recours à la doxographié et surtout, évidement, au lucrétien De rerum natura Eh blen. L'âme est un corps composé. Elle est la cause de la sensiblité et elle sent avec le corps, qui en est la condition. Elle naft et elle meurt avec le corps mals elle est relativement indépendante de celui-ci, puisqu'elle a des facultés qui lui sont propres et que le corps ne possède pas. Elle est formé de trois (souffle, chaleur, substance innomée) ou quatre éléments. Les savants ne sont pas tous d'accord sur la présence de ce quatrième elément, mais le poème nous l'explique: II n'est point de chaleur a laquelle de l'air ne se trouve également melé (III 234; trad. Ernout). En outre, ils ne s'accordent pas sur la nature de cette substance innomée. Est-elle semblable a la quintessence d'Aristote et au heegemonikón des stoiciens? Enfin, pulsque l'ame est un corps com:posé et pulsque tout composé se décompose, l'âme est mortelle. Et pulsque l'âme est mortelle, la mont n'est rien par rapport à nous. 
Assim como não só a alma aristotélica é uma resposta à alma platônıca mas ambos; Platăo e Aritóteles, assumem posiçăo diante dos pré-socráticos, assim também o epicurismo náo só como que responde aos pré-socráticos mas, ainda, responde a Platăo e Aristóteles'.

O que distingue principalmente Aristóteles de Platăo $\theta$ a ausência de perspectiva escatológica. Para o Estagirita, a mente, imortal embora, náo assume a individualidade do homem, năo assume a responsabilidade pelo seu comportamento. Epicuro distancia-se de ambos por năo aceitar qualquer imortalidade a năo ser a dos Deuses, para năo mencionar a eternidade dos átomos e do vazio.

Ainda que se encontrem também nas Kyriai Doxai e na Carta a Meneceu afirmaçбos a respeito da alma, da sensação e da morte, é nos parágrafos sessenta $\theta$ três $\theta$ sessenta $\theta$ oito da Carta a Heródoto que Epicuro define a natureza da alma, $\theta$ 6 sobretuto pela análise desses parágrafos que podemos defini-la, embora sejam inevitáveis as referências aos doxógrafos e principalmente ao lucreciano De rerum natura, documento epicúreo por exceléncia.

Parece ocioso afimar que o princlpio da teoria epicurista da alma consiste em que esta é material. Segundo o epicurismo, há no universo átomos $\theta$ vazio, $\theta$ todos os seres se compoem desses dois constituintes ${ }^{2}$. A alma, pois, é para Epicuro, assim como para Demócrito, um composto atômico.

Le-se na Carta a Heródoto ( $(63-8)$ que, "relativamente às sensaçбes e às afecçठes (...), é preciso considerar que a alma $\theta$ um corpo composto de particulas finas, disseminado por todo o agregado, muito semelhante a um sopro que tem uma mistura de calor $\theta$ é cá semelhante àquele e lá, a este. Há uma parte que, pela finura das particulas, assume muita variaçáo também desses elementos $\theta$, por isso, está mals em con-senso com o resto do agregado. Tudo isso mostram as faculdades da alma, as afecçбes, a facilidade de movimento $\theta$ de pensamento e tudo aquilo cuja privação nos faz morrer.

E ainda é preciso reter que na alma está a causa maior da sensaçáo. $\S 64$ Certamente não a teria assumido se nă̈o fosse de certo modo protegida pelo resto do agregado. Mas o resto do agregado, tendo-lhe propiciado aquela causa, ele próprio participa de tal acidente que vem dela, năo todavia de tudo o que ele possui. Por isso, tendo-se ido embora a alma, ele năo tem sensaçăo, pois nâo era ele que, em si mesmo, possula essa faculdade, mas a tinha propiciado a uma outra colsa que tinha vindo a ser justamente com ele e que, através de uma força constitulda em torno dela, pelo movimento perfazendo imediatamente 0 acidente sensivel para si mesma, a ele o devolve, graças à contigüldade $\theta$ ao con-senso, segundo disse. § 65 Por isso é que, estando a alma no corpo, mesmo que quatquer outra parte se tenha ido embora, jamais há ausêncla de sensaçáo. Se,

$1-$ Ct. Robin, 1963:52; Brun, 1974:71 et segs.

$2-$ Ct. Lucr. $1445-50$ 
porém, ela morre neste lugar quando se desfaz aquilo que a protege, quer no seu todo quer em parte, se ela permanecer, preserva a sensaçăo, mas, permanecendo o resto do agregado, todo ele ou em parte, năo tem sensaçăo, tendo ela ido embora, qualquer que seja o número de átomos que concorre para a natureza da alma. E ainda: desfeito o agregado no seu todo, a alma se dispersa e năo mais tem as mesmas faculdades, nem se move $\theta$, sendo assim, náo possui sensaçáo. $\S 66 \mathrm{De}$ fato, nåo é possível pensá-la sentindo nåo estando nesse conjunto e no uso desses movimentos, quando o que a protege $\theta$ a envolve năo $\theta$ aquilo onde agora está e onde tem esses movimentos.

'Escólio: Diz também em outras passagens que ela é composta de átomos muito lisos e muito redondos que superam de muito os do fogo. 'Menciona' também uma parte irracional dela disseminada pelo resto do corpo e a parte racional do torax, como fica evidente a partir dos temores e da alegria. O sono se produz quando as partes da alma, disseminadas por todo o composto, se reúnem ou se afastam, ou såo expulsas pelos choques.'

$\S 67$ Mas ainda isto: É preciso observar que nós falamos do incorporeo, segundo o uso mais ' comum do termo, sobre o que seria pensado por si mesmo. Por si mesmo não é possivel pensar o incorpóreo, exceto o vazio. Mas o vazio nem pode fazer nem ser afetado, mas apenas propicia aos corpos movimentos através dele. Sendo assim, os que dizem que a alma $e$ algo incorporeo falam coisas văs, pois ela não poderia nem fazer nem ser afetada se fosse tal. De fato, $\S$ 68 os acidentes a respeito da alma permitem captar nitidamente tanto um como 0 outro.

Portanto, todos esses raciocínios a respeito da alma, se aiguém os referir às afecçóes e às sensaçóes, se se lembrar do que foi dito no inicio, ele os verá suficientemente abrangidos por esses esquemas para que, a partir deles, possam ser precisados com segurança parte por parte ${ }^{3}$.

Vejamos. A alma é um corpa. Este corpo é formado de particulas finas. Ora, segundo Epicuro, inúmeros, embora năo infinitos, săo os tamanhos $\theta$ as formas dos átomos. E, em vista da rapidez das faculdades da alma, é necessário que as particulas que a compoem sejam formadas dos menores átomos, $\theta$ dos mals polidos ou lisos 4 .

A alma está disseminada por todo o agregado que constitui o corpo e abrigada por ele. Que está protegida pelo ıcorpo mostra-o a experiência. Existe enquanto em união com ele. Quando este se desfaz, dispersa-se. A idéla, retomada por Lucrécio, $\theta$ de que o corpo recobre ou envolve a alma. Dal chamá-la Epicuro tó stegázon $(\$ 65-6)$.

Da leitura do parágrafo sessenta $\theta$ tress, depreende-se que há três partes na al-

3 - Texto estabelecido por Conche (1977). Tradução da Professora Anna Lia A. de A. Prado.

4 - Cf. Ep. Her. $\S 66$ sch Parece-me interessante lembrar Demócrito (Artist. De an. 12, 404 a 6-9), embora segundo Democrito as figuras fossem semelhantes aos átomos esféricos do fogo e segundo Epicuro, a crermos no escólio do parágrafo sessenta e sels, distintas. (Bollack, 1971:223). 
ma: sopra, calor, e uma parte sem nome, que os estudiosos discutem. De Witt, por exemplo, reconhece no texto da Carta a presença de uma terceira parte, superior ao sopro e ao calor quanto à sutileza das suas particulas, mas discorda de que a chamemos uma parte sem nome5.

Plutarco cita nåo apenas três mas quatro elementos na alma segundo. Epicuro $\theta$ ridulariza o terceiro elemento da Carta, assinalando que o princlpio que determina o jutgamento, a memória, a amizade, o odio - o princlpio que raciocina - depende de um elemento sem nome $\theta^{6}$. E convém lembrar os testemunhos de Lucrécio, principalmente, $\theta$ de Aécio, que também mencionam quatro elementos ${ }^{7}$. Diz Aécio que a alma, segundo Eplcuro, $\theta$ urna mistura de fogo; ar, sopro vital $\theta$ um elemento sem nome.

Assim, é provável que haja de fato uma parte sem nome no parágrafo sessenta e três da Carta: parte que, pela finura das suas particulas, está mais em con-senso ${ }^{8}$ com o resto do agregado, equivalente à quarta quaedam natura de Lucrécio $\theta$ e a causa principal da sensibilidade ${ }^{9}$. É terceira na Carta. Se os doxógrafos e eplgonos mencionam quatro elementos, $\theta$ o De rerum natura que explica o quarto: diz que nåo há qualquêr calor ao qual náo esteja também misturado ar (III 234). Mais uma vez é interessante lembrar DeWith, que considera inexata a afirmaçăo de que a alma se compóe de quatro elementos $\theta$ acusa Lucrécio de sugerir que para Epicuro o número quatro eanónico ${ }^{10}$. Outros estudiosos, porém, entre os quals Bailey, absolutamente năo duvidam da afirmaçăo lucreciana" ${ }^{11}$. De fato, é o năo constarem da Carta a Heródoto as atribuiçס̋es especfficas dos elementos o que tem dado margem às diferentes interpretaçoes.

Lembra Bailey que o De rerum natura apresenta inicialmente apenas calor e uentus, o calor $\theta$ o sopro do parágrafo sessenta e trés da Carta, $\theta$ só adiante menciona o terceiro elemento, aer, e o quarto elemento, a quarta quaedam natura ${ }^{12}$. Năo acredita, porém, que o Poeta se houvesse afastado da teoria do Mestre. Apoia-se o crftico nos testemunhos de Aécio e Plutarco e aventa a hipótese de que aqui, como noutros passos, o Poeta seguisse a perdida Megálee Epitomée $\theta$ de que, na Carta, 0 Mestre esboçasse, apenas, algo já do conhecimento do discipulo Heródoto.

Entendem alguns estudiosos que a quarta natura de Lucrécio (ou terceira de

$5-(1954: 198)$

6-(Adu. Col 20, 1118d). Este fragmento haveria dado origem a uma confusáo entre animus e quarta natura.

7 - Cl. respectivamente Lucr. Ill 231 et seqs e Aet. IV 3,11 (Usener, 1966:Ir. 315).

8 - "Con-senso" traduz sympátheia que o De rerum natura traduz por consensus, algo assim como "sensibilidade ou sensaçấo conjunta". Ct. lll 740 e também 153.

9-Cf. Lucr. III 237-42.

$10-(1954: 198-9)$.

$11-(1928: 580$ et seqs).

12 - Cl. respectivamente III 121 corpora caloris $126-7$ uentl calidique uaporis semina 128 calor ac uentus ultalls 233 uapor porro trahit aera secum 240-1 quarta quaedam natura necessest adtribuatur. (No verso 122, aer estaria no seu sentido corrente.) 
Epicuro), que domina no corpo todo ${ }^{13}$ ou está mais em con-senso com o resto do agregado, não só se assemelha à quinta essência de Aristóteles mas também ao heegemonikón dos estóicos. Este ponto é delicado. No De rerum natura o equivalente do heegemonikón seria consilium regimenque, $\theta$ se dissermos que a quarta natura de Lucrécio se assemelha ao heegemonikón dos estóicos, corremos o risco de con. fundir animus $\theta$ quarta natura.

Afirma ainda a Carta que a causa maior da sensibilidade está na alma ( $\S$ 63). A afirmaçăo é clara e fica bem explicada: o resto do agregado participa da sensação que vem da alma (§ 64). Paralelamente, a sensação só é possível enquanto a alma permanece no corpo $\theta$ graças ao con-senso que há entre este e ela. Os seus átomos, extremamente móveis, penetram esse corpo em todos os seus recônditos: ferida por um estrmulo, os seus movimentos causadores de sensaçăo, confinados aos escassos limites desse corpo, transmitem-se a ele até que ele mesmo possa também sentir ${ }^{14}$. Este con-senso, aliás, é condição nåo só da sensibilidade mas da vida ${ }^{15}$ : a alma deve a sua existência ao fato de estar contida num corpo, visto que ela própria nåo tem coesão interna ${ }^{16}$

Pois bem. Ambos sentem: o corpo, que propicia à alma a capacidade de sentir, dela recebe a sua própria parte na sensibilidade ( $\S 64)$. Entretanto, o corpo năo participa de tudo o que a alma possui: memória, inteligência e razáo, vontade, medo, alegria, embora violentas comoçōes do esplrito possam estender as suas manifestaçőes através do corpo ${ }^{17}$

Epicuro atribuiu origem comum à alma $\theta$ ao corpo quando afirma que este propicia à sensibilidade a outra realidade nascida ao mesmo tempo que ele (§ 64). Escreve Aécio ${ }^{18}$ que, para Epicuro, o esperma é uma parte destacada da alma e do corpo. Este seria também o pensamento de Demócrito ${ }^{19}$. Ora, visto que tudo o que nasce com o corpo deve morrer com o corpo, a alma deve morrer ${ }^{20}$. Além disso, tão intimo $\theta$ con-senso entre corpo e alma que não se pode imaginar (epicureamente falando) uma alma vinda de fora a penetrar no corpo no momento do nascimento 21.

Como se depreende do parágrafo sessenta e cinco, a alma compoe-se de menor número de átomos que o corpo, no que Epicuro diferiria de Demócrito 22 . $O$ texto epicú-

13 - Lucr. III 281

14 - § 64: Lucr. III 246-50;331-6. V. também Sex. Emp. Adu. dogm. I (math. VII) 267 (Usener, 1966:tr.310).

15 -. Lucr. III $337-49$.

16 Giussani (1896:211), citando Brieger, distingue dois tipos de corpos. Os primeiros ( mixturae), por náo ter coesăo, precisam de.um corpo do segundo tipo (texturae) que os contenha.

17 - Cf. Lucr. III 152-60.

18 - V 3,5 (Usener, 1966:tr.329).

19 - Ct. DK 68 A 141.

20 - Ct. Aet. IV 7,4 e Lact. Diu. inst III 17,33 (Usener, 1966:fr.336).

21 - Ct. Lucr. III 325-49; v. também 445 et seqs.

22 - Id. Ibld. 370 et seqs; este $€$ o único registro dessa opiniáo democritiana. 
reo talvez nâo seja muito claro ${ }^{23}$. Confirma-o no entanto a experiência: a perda da alma năo implica diminuiçăo nem no tamanho nem no peso do corpo. Confirma-o também - De rerum natura. Ensina-nos o Poeta que náo só os elementos da alma săo multo menores que os de que constam o nosso corpo $\theta$ as nossas viceras, mas também săo inferiores em número e, raros, estáo disseminaodos pelos órgăos (III 374-95).

$E$, finalmente, o principio da teoria epicúrea da alma: esta 6 corpórea, ou nšo poderia nem agir nem ser afastada incorpóreo por si mesmo, como uma natureza completa, $\theta$ só o vazio - $\theta$ este, que é por definiçăo intanglvel ${ }^{24}$, năo pode nem agir nem ser afetado ( $\$ 67)$-. Ora, responsável pelo movimento, a alma age; causa da sensaçáo, $\theta$ afetada; logo, é necessário que seja corpórea a sua natureza ${ }^{25}$. Tăo importante quanto afirmar que a alma é mortal $\theta$ afimar que $\theta$ um corpo (§ 63). Afirmara-o Demócrito, afirmá-lo-á o Poeta.

Assim, parece-me possivel destacar nos parágrafos sessenta $\theta$ três a sessenta $\theta$ oito da Carta as seguintes afirmaçőes: a) a alma é um corpo; b) é responsável pela sensibilidade e sente com o corpo; c) nasce e morre com o corpo; d) compóe-se de três (ou quatro) elementos; e) goza de relativa independência em relação ao corpo, visto que tem faculdades que este não tem (§ 64).

Há no entanto algo que é preciso explicitar. Diz Epicuro que a alma é um corpo muito semelhante a um sopro que tem uma mistura de. calor e é cá semelhante àquele e lá, a este ( $(63)$. Isto quer dizer que a alma (que é formada de particulas finas) por causa de umas das suas!particulas é semelhante a um sopro e por causa de outras é semelhante ao calor. A experiência confirmará a asserção: sempre que se dissipam fugindo alguns corpos de calor e se exala ar pela boca, a vida imediatamente deserta as veias $\theta$ deixa para trás os ossos ${ }^{26}$. Entretanto, não devemos imaginar que a alma se compóe de um "sopro quente", mesmo porque o sopro justamente $\dot{\theta}$ frio; nem imạginar que se compóe de átomos de vento e de átomos de calor, pois náo hấ tal.

Permanece o problema das atribulçóos especfficas dos elementos. Essas atribuiçðes năo constam da Carta, e os testemunhos que temos săo mais uma vez o de Aécio e o do poema lucreciano.

Segundo Lucrécio, a quarta natura é responsável pelos movimentos causadores de sensibilidade (III 241-57); o calor, pelo ardor e pela ira; o sopro, causa do movimento; $\theta$ companheiro do espanto $\theta$ do horror; 0 ar, da tranqüilidade (III 288-315). E segundo 0 autor da Xynagoogée per areskóntoon, o sopro $\theta$ responsável pelo movimento; 0 ar, pela tranqüilidade; o fogo ou calor, pelo calor do corpo e 0 elemento sem nome, pela sensaçăo, visto que esta năo está llgada a nenhum dos elementos

\footnotetext{
23 - Cf. § 65: "qualquer que seja o número de átomos que concorre para a natureza da alma".

24 - Her. § 40; Lucr. 1437-9.

25 - Cf. Her. § 63.67; Lucr. 1 304; III 161-76. V. támbém Arist. De an 11,403a 25.

26 -- Lucr. III 121-3.
} 
mencionados ${ }^{27}$. Acredita-se, em geral, que Eplcuro nâo teria pensado na anâlise psicológica na qual pensou o Poeta, e que estaria mais próxima da idéla original do Mestre a afirmaçăo de Aécio.

Alguns estudiosos discordam das atribuiçбes dos elementos da alma. Rist, por exemplo ${ }^{28}$, opōe restriçס̄es à funçåo do sopro (pneúma, aura) como responsável pelo movimento. Vê um resquício de áristotelismo na afirmaçăo de Aécio e lembra que, segundo o De rerum natura, o sopro se liga à mente fria dos cervos $\theta 0$ único movimento gerado por ele $e$ o tremor causado pelo medo ${ }^{29}$. Este ponto é delicado. No quarto livro do poema $\theta$-se que o ar móvel impulsiona o corpo assim como as velas $\theta 0$ vento levam a nau (892-906). Ora, o Poeta distingue aer ("ar") e aura ("sopro"), sendo esta o "ar em movimento" e equivalendo a uentus. Como no mencionado passo do livro IV o ar é móvel, deve ser entendido como uentus ou aura (ou pneúma) e assim, ao meu ver, o poema desmente a opiniăo do sábio ${ }^{30}$.

Também me parece interessante lembrar que năo nos resta, diretamente de Epicuro, uma divisão da alma. No escólio ao parágrafo sessenta e seis da carta, lé-se que há nela algo irracional (ti álogon) disseminado pelo resto do corpo, $\theta$ o racional (tó logikón) localizado no tórax. O De rerum natura, por sua vez, distingue animus ("ånimo" ou! "espirito") $\theta$ anima ("alma"), que se mantêm intimamente unidos, formando uma só natureza; oprimeiro situado na região média do peito; a segunda disseminada pelo corpo todo: ambos mortais ${ }^{31}$. E Aścio ${ }^{32}$ escreve que a alma, de acordo com Epicuro [e Demócrito], se compóe de duas partes: a racional (to logikón), que tem a sua sode no peito, $\theta$ a irracional (tó álogon), disseminada por todo o agregado que constitui o corpo; e chama ao racional de Epicuro to heegemonikón.

Talvez se deva pensar que, embora não conste da Carta a Heródoto, a distinção se encontraria noutros escritos do Mestre, pois năo só pertence à tradiçăo helênica mas também se encontraria em Demócrito.

Por outro lado, a distinção entre to álogon (anima) e to logikơn ou, melhor, to lógon échon (animus) teria sentido quanto às funçరes mas não quanto à estrutura ffsica, razão pela qual a teria o Mestre omitido na Carta, em que focaliza em linhas gerais a ffsica do sistema ${ }^{33}$. É-se tentado a relacionar o irracional ou a-racional à psychée e à anima lucreciana, $\theta$ o racional à diánoia e ao animus. Náo obstante, $\theta$ preciso notar que o racional, assim como o animus, $\theta$ igualmente emocional $\theta$ volitivo, ao passo que para Epicuro diánoia significa: a) "faculdade capaz de apreensâo imediata de imagens"34; b) "faculdade capaz de apreensão imediata do invisivel" (Her. §62); c)

27 - IV 3,11 (Usener, 1966:fr.315).

28 - (1977:76-7).

$29-$ Cf. III 290-1;299-301.

30 - Também no livro VI (685) se encontra a noçâo de que o vento e "ar móvel": Ventus enim fit ubi est agitando percitus aer. V. Ep. Pyth $\S 105$.

31 - III 117-29; 136-60;417-24.

32 - DK 68 A 105 (Usener, 1966:fr.312).

33 - Segundo ele mesmo afirma (§ 35-6).

34 - Her. § 38.49-51; KDXXIV. 
"faculdade capaz de apreensăo de um princlpio, através do raciocínio"35. A dianóia será, portanto, racional masnáo emocional e volitiva.

Surge aqui um ponto que tem sido objeto de discussరes sem fim: a parte sem nome pertence a ambas as partes da alma ou apenas a uma e náo à outra. Ora, a Carta não estabelece a bipartiçăo e atribui à psyché também o pensamento (§63). É verdade que a atribuiçăo de faculdades intelectuais à psyché năo implica a náo distinçăo entre álogon e logikón: o Mestre pode havê-los incluldo sob a mesma denominaçăo. O Poeta igualmente inclul sob um só nome animus $\theta$ anima ao apresentarThes as provas da mortalidade. Ao meu ver, porém, justamente o incluilos sob um so nome indica terem as partes a mesma composiçáo e, nesse caso, a parte sem nome, se existe uma, pertence a ambas.

Restaria dizer ainda uma palavra a respeito da morte. Segundo Lactâncio, Epicuro diz que năo se devem temer os castigos do infemo porque as almas perecem após a morte e o infemo absolutamente năo existe ${ }^{36}$.

$\mathrm{Na}$ verdade, o epicurismo surgiu exatamente para livrar o homem dos seus temores. Se a imortalidade da alma havia sido negada por Democrito, o epicurismo tem nessa negaçăo a pedra angular da sua doutrina: a alma é material e mortal. Realmente, afima Epicuro que, ao desfazer-se o agregado que constitui o corpo, a alma se dispersa, nåo tem mais poder nem se move nem sente; volta aos átomos que a compunham, estes, sim, indestrutfveis (Her. §65-6).

Ora, tememos dores terriveis e eternas para a nossa alma $\theta$ tememos a propria insensibilidade do corpo no estar morto como se isso nos atingisse, o que é irracional pois todo bem $\theta$ todo mal residem na sensaçăo ${ }^{37}$. a morte não nos diz respeito pois quando existimos ela náo está presente e quando está presente já năo existimos.

Afirma também Epicuro que nada há de temivel na vida para quem sabe que nada há de temivel na năo-vida $\theta$ que nåo the pesa ao sábio viver como năo o assusta morrer (Men. §126). Vivemos uma só vez $\theta$ a consciência de que a morte nada é para nós livra-nos de desejar a imortalidade (Men. §124-5).

Em suma, afasta-se totalmente Epicuro da concepçáo órfico-pitagórica e platônica de uma alma imortal $\theta$ individual. Afasta-se também da concepçáo aristotélica da alma-forma incorpórea e da mente incorporea $\theta$ imortal. Defende, como Dembcrito, a materialidade $\theta$ a mortalidade da alma $\theta$ da mente, a idéntica natureza da alma sensitiva $\theta$ motora e da alma pensante e volitiva, a noçáo de que os seus átomos componentes sáo extremamente pequenos $\theta$ extremamente móveis $\theta$ a de que as suas faculdades, visto que a sua definiçăo é puramente materialista, se exercem mediante contato. E visto que os átomos têm como qualidades únicas forma, volume e peso, o sensivel pode provir do insensivel, da mesma forma que o clinamen, automático, espontâneo e indeterminado no espaço e no tempo, resulta num movimento consciente de voliçăo.

35 - Her. §78; KD XX. (Cf. Balley, 1928:416 n 2).

36 - Diu. Inst. III 117,42 (Usener, 1966:tr.341, 18-20).

37 - Her. §81; KDII. 
BIBLIOGRAFIA

BAILEY, C. The Greek Atomists and Epicurus. Oxford, Clarendon, 1928.

BOLLACK, J. et alii. La lettre d'Épicure. [Paris] Ed. de Minuit |1971|.

BRUN, J. L'épicurisme. Paris, PUF, 1974.

CONCHE, M. Épicure: lettres et maximes. Paris, Éd. de Mégare, 1977.

DeWITT, N. W. Epicurus and his Philosophy. Minneapolis, Univ. of Minnesota, 1954.

DIELS, H. \& KRANS, W. Die Fragmente der Vorsokratiker. Bertin, Weidmann, 1954.

GLIUSSANI, C. Studi lucreziani Torino, E.Loescher, 1896.

RIST, J. M. Epicurus. Cambridge Ėngl., Cambridge Univ., 1977.

ROBIN, L. La morale antique. Paris, PUF, 1963.

USENER, H. Epicurea. Stuttgart, B.C Teubner, 1966.

TEXTOS

ARISTOTE De l'âme. Paris, “Les Belles Lettres”, 1980.

EPICURO (v. Bollack et alit, Conche).

LUCRĖCE De la nature. Paris, “Les Belles Lettres”, 1972. 